\title{
Rural Electrification and Small and Medium Entreprises' (SMEs) Performances in Mvomero District, Morogoro, Tanzania
}

\author{
Romanus Lucian DIMOSO \\ Mzumbe University, Economics Department, P.O.Box 5, Mzumbe, Morogoro. \\ Tanzania \\ e-mail: rdimoso@mzumbe.ac.tz

\section{Felician ANDREW} \\ Mzumbe University, Economics Department, P.O.Box 5, Mzumbe, Morogoro. \\ Tanzania \\ e-mail: felicianandrew@gmail.com
}

\begin{abstract}
In recent years, Tanzania has been experiencing increasing in number of SMEs business in rural areas particularly in areas where Rural Electrification Programs (REA) have been well implemented. These programs are always associated with low connecting costs which attract many households to use the energy. This study examined the effects of rural electrification programs to the SMEs' performances measured in revenues collected by these SMEs. The study was done in Mvomero district, Morogoro. The Ordered Logistic Regression (OLR) model was employed in the data analysis. Tests such as Oparallel and Brant were used to assess the assumptions of parallel lines. Findings on the determinants of electrical adoption reveals that 59.385 percent of SMEs' owners who have higher revenues adopt electricity while education influence on the electrical adoption among SMEs' owner is only 8.29 percent. Moreover, findings on the effects of rural electrification programs on SMEs' performances shows that distance to the nearby transformer, willingness to pay for REA, affordability of the REA programs and adoption of the REA energy among SMEs increase SMEs performances significantly. Consequently, the government is advised to ensure that, through policies and other regulatory roles that rural SMEs get growing up. This can be done if these rural SMEs are enabled to solicit credits from financial facilities to expanding their businesses and making beneficial utilization of REA services. The economic outcome, through multiplier effects in employment creation and subjective economic welfare, might be tremendous.
\end{abstract}

Keywords: Rural Electrification, SMEs' Performance, REA programs, Mvomero District. 


\section{Introduction}

Tanzania is a low-middle income country, with a population of about 57.6 million in 2020 (National Bureau of Statistics, 2020). About $73 \%$ of the population lives in rural areas. Despite a high rate of growth of $7 \%$ in the past decade, poverty reduction has been slow, with approximately 12 million of citizens living in dire poverty while a significant portion of the nonpoor population lives just above the poverty line and risks falling into poverty unless proper measures are in place (World Bank, 2017). In the next fifteen years, Tanzania's labor force is expected to increase from 20 million in 2014, to close to 50 million by 2030 (WB, 2020). Access to affordable, reliable and efficient electricity supply is vital for the increased productivity needed to generate jobs, enhance the living conditions of Tanzanian households and support the attainment of the country's socioeconomic goals.

Rural electrification is described as a process of improving electrical accessibility to remote and rural part of the country that can be achieved through the mini-grids, national grids networks or the use of expanded renewable energy system such as the use of solar panel or wind power plant and other sources such as bio fuels. Rural electrifications programs in Tanzania began in 1970s with the major aim of increasing accessibility and availability of the reliable sources of power which has been beneficial for multipurpose usage in industrial, domestic or in different commercial activities. Rural electrification is one of important strategy for the increased growth of the economy and socioeconomic development of a country; therefore it has been addressed in a national framework for the reduction of poverty as well as in the Tanzania Development Vision 2025 (URT, 2018).

Access to affordable and reliable electricity is vital for Tanzania's attainment of its socioeconomic goals such as expanding access to affordable, reliable and modern energy; and ensuring operational and financial sustainability of the sector. Electricity is a fundamental driver of development of SMEs. The growing businesses trend in rural areas in Tanzania increases a need for the electrification in order to facilitate the fastest growing of the sectors and improving the livelihood of the people in the rural areas (Ng'ang'a et al,. 2009). Tanzania government has confirmed its commitment to promote SMEs as the result of its great contribution in the gross domestic product (GDP) and employment of which these fall into development programs and policy implications.

Balla (2003) argued that the successfulness of different programs and polices worldwide can only be achieved if there is availability and accessibility to power/energy of which is more important to the rural household in order to increase their production and livelihood. Although, until 2014 the global shortage of electricity was 16 percent with severe burden experienced to the poor and marginalized groups.

Table 1: Small Business Owners by Areas in Tanzania

\begin{tabular}{|l|l|l|r|l|}
\hline Total SMEs & Dar es Salaam & Other Urban & Rural Areas & Zanzibar \\
\hline $2,754,697$ & 405,902 & 814,557 & $1,459,167$ & 75,071 \\
\hline
\end{tabular}

Source: MSMEs National Baseline Survey, 2013

Table 1identifies that majority of SMEs activities are being carried in rural areas in Tanzania. These different kinds of SMEs can be categorized based on the characteristics of their activities, number of employees and capital available for investment (Table 2) as well as the kind of energy 
used during productions or provision of services. Activities such as fish drying, production of charcoal, bricks burning, ceramics firing and the making of local beer to a large extent in most of these rural areas are using biomass as the source of energy. On the other hand, saloons, bars, welders, different types of shops and wood processing SMEs normally use electricity for the refrigeration, entertainments and lightning or processing and cutting woods into pieces (Sawe, 2004).

Moreover, as postulated in the World Bank report (2005) that there is no universally accepted single definition of SMEs in the world. Although there doesn't exist single acceptable definition of small businesses universally, in the view of this study a small and medium enterprises refers to individually owned and controlled businesses at a local place, the members of the business are mostly but not usually members of the family living under the same roof. The management of the business is individual based so do ownership.

In the context of Tanzania SMEs policy of 2003 provides that micro enterprises are those engaging up to 4 people in most cases family members or employing capital amounting up to Tshs 5 million. The majority of SMEs fall under the informal sector (United Republic of Tanzania SMEs Policy, 2003). Small enterprises are mostly formalized undertaking engaging between 5 to 49 employees with capital investments from Tshs 5 million to Tshs 200 million. Medium enterprises employ between 50 to 99 people or use capital investments from Tshs 200 million to Tshs 800 million.

Table 2: Government of Tanzania's Categorization of Business Size

\begin{tabular}{|l|l|l|}
\hline Business Size & Number of Employees & $\begin{array}{l}\text { Capital Investment in Machinery } \\
\text { (Tzs) }\end{array}$ \\
\hline Micro Enterprise & 1 to 4 & Up to 5 million \\
\hline Small Enterprise & 5 to 49 & Above 5 to 200 million \\
\hline Medium Enterprise & 50 to 99 & Above 200 to 800 million \\
\hline Large Enterprise & $100+$ & Above 800 million \\
\hline
\end{tabular}

Source: MSME National Baseline Survey, 2013

The Tanzania Development Vision (TDV) 2025, highlighted small and medium-sized enterprises (SME) sector as one important contributor to the country's long-term development. It is estimated that Tanzania's SME sector consists of more than 3 million enterprises which contribute to $27 \%$ of overall GDP. Most of them are in the agricultural sector of which majority of the people employed in agriculture are living in rural areas, and more than half are owned by women. Therefore, examining the rural electrification impacts on the SMEs performance is important in assessing both electrification program and the difference between SMEs using energy and those which are not for the purpose of improving policy and these programs at the same time.

\subsection{Rural Electrification Programs}

Rural electrification program are defined as programs that aim in facilitating processes of bringing electrical power to remote and rural areas of the country in order to enhance the livelihood improvement. The history of rural electrification programs in Tanzania began in 2000s but officially launched in 2007 after the establishment of the Rural Electrification Agency (REA) 
whose main role is to promote and facilitate improved access to modern energy services in rural areas of Mainland Tanzania.

An improved energy supply in the rural areas through public and private sector participation, will contribute significantly in improvement of the livelihoods of the rural population and the attainment of sustainable economic growth. For these reasons, the Rural Energy Board (REB), the Rural Energy Agency (REA), and the Rural Energy Fund (REF) were established and entrusted with the role of promoting, stimulating and facilitating improved access to modern energy services in rural areas through empowering both public and private sector initiatives in rural energy. The Rural Energy Fund (REF) was established by The Rural Energy Act, 2005 for the purpose of providing grants to qualified project developers. The Fund represents a mechanism by which the Rural Energy Board (through REA) fulfills its mandate.

On the other hand, sources of funds for running these programs include:

i. Government, in an annual budgetary allocation

ii. Contributions from international financial organizations, multilateral and bilateral agencies and other development partners

iii. Levies of up to five percent $(5 \%)$ on the commercial generation of electricity to the national grid; as fees in respect of programmes, publications, seminars, consultancy services and other services provided by the REA

iv. development partners' contributions to Special Purpose Funds for rural energy

v. Interest or return on investments.

In Mvomero district alone, more than 21 villages have been connected with the REA program under three different phases of which under Phase I only two villages were connected with electricity while 20 and 2 other villages were later connected with electricity under Phase II and III respectively. The development of these projects has been associated with the increase of needs and the number of small businesses and vendors in the districts (URT, 2016)

\section{Literature Review}

\subsection{Rural Electrification and Performance of SMEs}

Scholars and researchers are having different opinions on the effects of rural electrification to the performances of the SMEs in the rural areas; with this diversity here are some of the studies that try to explain the electrification effects to the performance of the SMEs.

A TANESCO study of 1992 that assed the technical, financial and socio-economic impact of REA programs in four districts in Tanzania revealed that three of four energy consumers were entrepreneurs who were dealing with small business mentioned small shops, restaurant (cafeterias) and guest houses. Moreover, the remaining one third of the population used electricity for running light industries in their areas. Therefore, an investment in rural electrification programs is the decision to improve not only the availability and accessibility of the energy but also allowing the smoothly growing of the SMEs sector in the economy (TANESCO, 2016).

Person and Swanson (1996) investigated the effect of electricity supply on the performance of SMEs by making comparisons between SMEs connected in the national grid with those that were not connected to the national grid. The study discovers that all firms that were utilizing the 
electricity under the country's grid had good performances compared to firms that had no electricity at all.

Maleko (2005) made a research on effects of electricity supply services on SMEs in Tanzania. From findings it was shown that SMEs growth rate was noticeably being higher in areas with electrical services comparing to those areas that are not connected with electricity. The livelihood situations of most entrepreneurs as well as employees have changed due to the electrification projects which increase performance of SMEs. Improvements in financial assets have been experienced together with an increase of income. Maleko (2005) concluded that rural SMEs are strengthened by increased availability and the reliability of different electrification projects. These stimulate the establishment and expansion of SMEs. Therefore, blackout of electricity or power rationing for these types of enterprises causes low production or stop services provided resulted into low income and slow down a strategy for poverty reduction.

Shahidur et al. (2012) found that businesses in rural areas of developing countries with access to electricity such as home businesses, small commercial shops, grain mills, saw mills, coffee and tea processing and other small-scale enterprises can benefit from rural electrification programmes. In his book "Rural Electrification and Rural Development" Cook (2012) points out that the effect of rural electrification on small businesses should be determined by the nature of the local community, the complimentary programs and the ability of rural entrepreneurs (Shahidur et al., 2012).

Tarun et al., (2013) reports a study on effects of electrical energy access to rural small and medium enterprises. The study intended towards assessing impacts of electrical accessibility on business operation as well as performance for these SMEs in rural areas in Bangladesh. Results are mainly based on a survey study conducted in Khulna, Paikgacha. The study found significant changes on cost of production and increased profit margins as the result of electrification. The study suggested that there is a need to increase number of stakeholders in different areas for improving amount of electrical energy produced in the grid electricity services and supporting rural electrification programs.

Akpan et al., (2013) study on Impact of Rural Electrification to Rural SMEs at Delta villages in Nigeria shows that, average SMEs that are connected with electrical grid in these communities are 16.2 percent higher chances of earning income comparing to SMEs found in communities that are not linked with the electrical grid. Rural electrification is effectively in enhancing development of improvement of rural and urban residents' livelihood as electricity has multiplier effects in the promotion of investment and welfare betterment. The study further showed that an increase access for capital for investments in electrical generation appliances, rural electricity enables projects in rural context to be able to use electrical devices.

Kidole (2015) did a study on contribution of rural electrification to household income in Moshi District, Tanzania. Specifically, the study aimed at identifying income generating activities undertaken using grid electricity, assessing the contribution of grid to household income as well as identifying the challenges in utilization of grid electricity services in income generating activities. The study identified among others, iron wedding, compact disc burning and grain milling as income generating activities influenced by presence of grid electricity. The household annual income ranged from $800,000 \mathrm{TZS}$ to $46,000,000 \mathrm{TZS}$ and there were statistically significant differences in income between households with grid electricity services and those without. In addition, the study identified reliability of services, high application standards, and higher bill as challenges associated with grid electricity services. The study concludes that grid electricity contributes to increased household income. Furthermore, the study recommends that, the 
government and development partners should secure necessary financial resources to invest in rural electrification.

In 2015, African Union conducted a study that examined effects of electricity supply in the growth of MSMEs revenues in Ghana by the use of the WB Ghana's MSMEs data that were collected in 2013 that comprises of 710 MSMEs. The results showed that persistent power blackouts due to the shortage of electricity had negative effects in the growth of the MSMEs revenues. The study further highlighted that, most of the perishable commodities were rotten and hence affecting these businesses heavily and affects owners' capital. In order to solve these problems that have been seen to lower the growth rate of the MSMEs in Ghana, the study recommended that, Ghana government and African states at large are required to empower the rural electrification programs through establishing policies and initiatives that lead to the proper and timely implementations of the rural electrification programs that will be having a goal of improving people's life. Through proper investment in the energy sector, African governments will stimulate the expansion of the private sectors in their countries which in turn will open door for the expansion of employment opportunities and hence economic growth (AU, 2015).

Gerald et al., (2018) report a study on the significance of rural electrification in Zimbabwe. The survey included key respondents from the rural electrification agency, provincial stakeholder and beneficiaries in Mudzi district sampled from a population frame of households, businesses, government departments and local leaders. The study concludes that rural electrification has been significant in social development, with low impact on economic development. Many cottage industries including tailoring and welding as well as grocery and workshops had sprung up due to the establishment of electrified rural service centers, this has enabled self-sustaining and repairs to be done within the major growth point thereby speeding up the turn-around times for most activities. The recommendation is that rural electrification in Zimbabwe should be suspended for the next 7 years. Given the shortage of financial resources in the country, the focus on electricity development of the country should be towards reducing or eliminating the energy deficit.

Antoine et al., (2017) did a study on effects of electrifications on rural household and business communities in testing resource based theory for entrepreneurship. The study findings showed that there is an important difference to entrepreneurship opportunities that accelerate the growth SMEs as electrification was reported to increase number of SMEs creation when there is an increase of electrification sites to 33 from 20. Therefore, effects of electrification projects were experienced to households and individual business entrepreneurs' income as well as increase of their faith and commitment of doing business. Also, future expectations of individuals are strengthened as their communities are connected to electricity. In addition to that, despite of the income gap between men and women, studies have found that electricity programs benefits women largely comparing to men. 


\subsection{Conceptual Framework}

Conceptual framework in Figure 2.1 shows the relationship between electricity adoption and connectivity with the SMEs performances

Independent Variables $\quad$ Dependent Variable

Adoption of Electricity

- Education

- Age

- Gender

- Marital Status

- Family Size

- Distance to nearest transformer

- Capital of business

- Credit Membership

\section{Connectivity of Electricity}

- Willingness to pay for electrification

- Experience in SMEs activities

- Affordability of electricity

- Quality of electricity

- Operating cost

Figure 2.1: Conceptual Framework

\section{Source: Own Construction, (2020)}

Despite of the above discussed literatures yet there are no studies that have discussed impacts of Rural Electrification Programs in the growth of SMEs in Tanzania. Therefore this paper examines impacts of REA programs in the growth of SMEs from the view of selected wards in Mvomero district. Mvomero is one of the six districts in Morogoro region of Tanzania. It is bordered to the north by the Tanga Region, to the northeast by the Pwani Region, to the east and southeast by Morogoro Rural District and Morogoro Urban District and to the west by Kilosa District. The district is situated between $8000^{\circ}$ and $10000^{\circ}$ South of the Equator and between longitudes $7000^{\circ}$ and $8022^{\circ}$ East in North East of Morogoro region. With the approximated 7,325 square kilometers of land, the district has 30 wards with famous wards being Melela, Mlali, Doma, and Mgeta which are the areas of the study while others includes Mzumbe, Lubungo, Mtibwa , Dakawa and so forth (NBS, 2019). 


\subsection{Theoretical Framework}

This study employed Cobb-Douglas production function to determine the technical relationship between regressors and regressand. Whereas, $\mathrm{Q}$ represented the quantity of productivity of SMEs (regressand), $\mathrm{L}$ and $\mathrm{K}$ represented the factors influencing SMEs production (regressors) and latter A represents the Total Factor Productivity (TFP) that measures the change in output that is not the result of the inputs. Typically, this change in TFP is the result of improvement in efficiency or technology. The alpha and beta characters reflect the output elasticity of the inputs. Output elasticity is the change in the output that results from a change in either labor or physical capital.

$Q(L . K)=A x L^{\beta} \times K^{\alpha}$

Whereby $Q$ is the quantity of products; Lis the quantity of labor; $K$ is the quantity of capital; $A$ is a positive constant or total factor productivity while $\beta$ and $\alpha$ are constants between 0 and 1 .

Electricity infrastructure and consumption or the use of electricity generally it increases with productivity and growth. A number of studies support the conclusion that electricity enhances productivity at the economy wide and the small and medium enterprises (Kirubi, 2008; Grimm et al., 2012). Many small manufacturing firms use electricity predominantly for lighting and communication.Overall, firms with access to electricity tend to have higher productivity than firms without. However, pre-existing conditions (location, access to finance, and management competence) have a strong impact on how access to electricity affects SMEs. Electricity access seems to have higher positive impact on productivity of SMEs (World Bank, 2008; Grimm et al., 2011).

\section{Data and Methodology}

\subsection{Data}

Through the cross sectional design a primary data collection techniques were used to collect data from Rural Energy Electrification sites at Mvomero district in Morogoro region of which 257 questionnaires were disbursed out of 720 SMES who were connected to the REA programs by the use of stratified random sampling which is more flexible than simple random sampling.

$n=\frac{N}{1+N\left(e^{2}\right)}$

Whereas;

$N$ - Total number of household heads engaging in SMEs connected to REA

$e$ - Random error at 5 percent level

$n$-Sample size

$n=\frac{720}{1+720\left(0.05^{2}\right)}$

$n \approx 257$

\subsection{Regression Model}

Ordered logit model is based on a continuous latent variable. The study used ordered logit model to investigate and determine the effect of variables of Education level of the respondents measured in years of schooling, Distance to the nearest transformer $(\mathrm{Km})$, Experience, Business Capital, Marital Status, Gender of the respondents, Credit Membership, Willingness to pay, Affordability and Operating Cost and the insignificant factors reported were Family Size, Age Squared, and Age of the respondents and impact of each variable on the likelihood of individuals 
to be placed at one of four income groups of less than $300,000 \mathrm{TZS}$, between 300,000 and 500,000 TZS, between 500,000 and 800,000 TZS and 800,000 TZS and above.

$y^{*}=\beta_{0}+\beta_{1} X_{1}+\beta_{2} X_{2}+\beta_{3} X_{3}+\beta_{4} X_{4}+\beta_{5} X_{5}+\beta_{6} X_{6}+\beta_{7} X_{7}+\cdots+\beta_{k} X_{k}+\varepsilon_{i}$

$y^{*}$ being different levels of income of SMEs

$$
\begin{gathered}
y^{*}=\left\{\begin{array}{c}
\text { less than } 300,000 \text { if } y^{*} \leq \mu_{1} \\
\text { between } 300,000 \text { and } 500,000 \text { if } \mu_{1}<y^{*} \leq \mu_{2} \\
\text { between } 500,000 \text { and } 800,000 \text { if } \mu_{2}<y^{*} \leq \mu_{3} \\
\text { above } 800,000 \text { if } \mu_{3}<y^{*} \leq \mu_{4}
\end{array}\right. \\
y^{*}=\beta_{0}+\beta_{1} \text { Educ }+\beta_{2} \text { DisTransformer }+\beta_{3} \text { BusCapital }+\beta_{4} \text { WTP }+\beta_{5} \text { MaritalStatus } \\
+\beta_{6} \text { FamilySize }+\beta_{7} \text { Gender }+\varepsilon_{i}
\end{gathered}
$$

\subsection{Estimation Techniques}

The ordered logistic model was used to examine relationship or effects of adoption of rural electrification and connectivity of rural electrification on the performance of SMEs, of which the performances of rural SMEs is measured in term of levels of income generated categorized into three levels of higher, intermediate and lower income in ordered scales (Greene, 2012).

The model is as follows:

$y_{i}^{*}=\beta^{\prime} x_{i}+\varepsilon_{i} \quad-\infty<y_{i}^{*}<-\infty$

Where

$y_{i}^{*}$ : Levels of income of SMEs

$\beta^{\prime}$ : Vector of parameters that should be estimated

$x_{i}$ : Observed vector of non-random explanatory variable, which shows the characteristic of $i^{t h}$ variable

$\varepsilon_{i}$ : Residual error, which is logistically distributed

Since $y_{i}^{*}$ is a latent variable, standard regression techniques are not applicable to estimate the sample size. If $y_{i}$ is considered as a discrete and observable variable which shows different levels of small and medium enterprises income, the relation between latent variable $y^{*}$ and observable variable $y$ is obtained from ordered logit model as follows:

$$
\begin{array}{lll}
y_{i}=1 & \text { if } \quad-\infty \leq y_{i}^{*}<\mu_{1} & i=1, \ldots, n \\
y_{i}=2 & \text { if } \mu_{1} \leq y_{i}^{*}<\mu_{2} & i=1, \ldots, n \\
y_{i}=3 & \text { if } \mu_{2} \leq y_{i}^{*}<\mu_{3} & i=1, \ldots, n \\
y_{i}=J & \text { if } \mu_{j-1} \leq y_{i}^{*}<+\infty & i=1, \ldots, n
\end{array}
$$

In which ' $n$ ' is the value for the sample size. ' $\mu$ ' and ' $s$ ' are the thresholds that define observed discrete answers and should be estimated. The probability of $y_{i}=j$ should be calculated by the following relation:

$\operatorname{Pr}\left(y_{1}=J\right)=\operatorname{Pr}\left(y_{1} \geq \mu_{j-1}\right)=\operatorname{Pr}\left(\varepsilon_{1} \geq \mu_{n-1}-\beta x_{1}\right)=F\left(\beta x_{1}-\mu_{j-1}\right)$

In cumulative probability expression, ordered logit model estimates the likelihood of person 'I' to be at ' $j$ th' level or less $(1 \ldots, j-1)$. It should be noted that the answer groups in ordered logit model are ordered.

Ordered logit model is expressed as follows: 
$\log \left[\frac{y_{j}\left(x_{i}\right)}{1-\gamma_{i}\left(x_{i}\right)}\right]=\mu_{j}-\left[\beta_{1} x_{1 i}+\beta_{2} x_{2 i}+\cdots+\beta_{k} x_{k i}\right]$

Whereby $j=1 \ldots, J ; I \ldots, n$

In which, $y_{j}$ is a cumulative probability of the following:

$y_{j}\left(x_{i}\right)=y\left(\mu_{j}-\beta^{\prime} x_{i}\right)=p\left(y_{i} \leq j \mid x_{i}\right)$

$\beta^{\prime}$ is the column vector and of $\beta_{1}, \beta_{2} \ldots \beta_{3}$ parameters and $x_{i}$ is the column vector of explanatory variables. $\mu_{j}$ is only dependent on probability of predicting category and is not dependent on explanatory variables. Furthermore, the other part,

$$
\beta_{1} x_{1 i}+\beta_{2} x_{2 i}+\cdots+\beta_{k} x_{k i}
$$

It is the independent part of the category. These two characteristics ensure that the answers groups are ordered and show that the results are a series of parallel lines.

In order to evaluate the hypothesis of equality of the parameters for all the groups, parallel regression test is used. This test compares the estimated model with a series of coefficients for all the groups with a model with a separate series of coefficients for each group. In this case, if the current model, which is the null hypothesis, is accepted, it proves that the status parameters are the same for all the answer groups. $x^{2}$ statistic in parallel regression test is calculated as follows:

$x^{2}=-$ LogLikelihood $_{C m}-\left(-2\right.$ LogLikelihood $\left._{G m}\right)$

in which, $\mathrm{Gm}$ and $\mathrm{Cm}$ represent the current and general model respectively. If the calculated $x^{2}$ in more than $x^{2}$ in the table, it indicates the rejection of the null hypothesis that means the current model is estimated correctly. Parameters are estimated by maximum likelihood estimation method, which maximizes the probability of categorization.

$L\left(y \mid \beta: \mu_{1}, \mu_{2}, \ldots \mu_{j-1}\right)=\prod_{i=1}^{n} \prod_{j=0}^{j}\left[\left(\mu_{j-1}-\beta^{\prime} x_{i}\right)-y\left(\mu_{j-1}-\beta^{\prime} x_{i}\right)\right]^{z i j}$

Where' $z i j$ ' is a binary variable. It equals to 1 when the observed group for person ' $I$ 'is ' $j$ ', and if they are not equal to zero. Newton-Raphson algorithm is used in maximizing process.

In this model, the interpretation of $R^{2}-$ pseudo is different and it does not have the typical interpretation. With the increase of the estimates of the model, its value also increases and its value is between zero and one. Berman and Benaque in 1985 introduced the classification accuracy to evaluate the goodness of estimates of the model, which expresses the percentage of correct and incorrect predictions of the dependent variable.

Regarding the interpretation of the coefficients, it should be noted that coefficients are not directly interpreted in this model. In case the predicting variable increases, changes in probability are dependent on two factors: one of them is the predicting value and the other is dependent on other variables; considering the fact that changes in probability are not constant, coefficients are not directly interpreted. Thus, marks are used to change the probability in this model for the extreme groups (first and last). For instance, the positive mark next to $\beta_{k}$ coefficient indicates that $x_{k}$ increase in predicting variable, decrease the probability of the first category $\left(y_{i}=1\right)$, while the probability of the last group $\left(y_{i}=j\right)$ increase, each act in the opposite direction. In such situations, the directions of the middle categories are not clear. The calculation of the marginal effect of one unit in $x_{k}$ predictor on the probability of ' $j$ ' category is as follows:

$\frac{\delta P\left(y_{i}=j \mid x_{i}\right)}{\delta x_{k}}=\left[\frac{\delta y\left(\mu_{j}-\beta^{\prime} x_{i}\right.}{\delta x_{k}}-\frac{\delta y\left(\mu_{j-1}-\beta^{\prime} x_{i}\right)}{\delta x_{k}}\right]=\left[\sigma\left(\mu_{j-1}-\beta^{\prime} x_{i}\right)-\sigma\left(\mu_{j}-\beta^{\prime} x_{i}\right) \beta_{k}\right]$ 
Of which $\mu_{j}=+\infty, \mu_{*}=-\infty, \sigma_{j}\left(x_{i}\right)=\frac{\delta y_{i}\left(x_{i}\right)}{\delta x_{k}}$

Making decisions about using variables' value in estimation is very important, because the marginal effect depends on the values of all explanatory variables. Since total probability always equals 1 , the total marginal effect for each variable is zero. But it should be noted that the marginal effect is not direct binary variable and it can be obtained by calculating the difference between the two possible probabilities.

\section{Discussion of Findings}

\subsection{Descriptive Statistics}

Results on Table 3 Column 3 shows that average age of 257 respondents participated in the survey was 34 years, this is good since it is the age of maturity for most of the respondents and hence have enough experience in the industry. Moreover, majority of the respondents have an average 9 years of schooling implying that most of the respondents have attained the secondary education. Nonetheless, average distance from SMEs businesses to the nearby transformer is 1.46 kilometers while the average capital to all SMEs in Mvomero is Tshs. 400,782.

Table 3: Descriptive Statistics

\begin{tabular}{l|l|l|l|l|l}
\hline Variable & $\begin{array}{l}\text { Observatio } \\
\mathbf{n}\end{array}$ & Mean & $\begin{array}{l}\text { Standard } \\
\text { Deviation }\end{array}$ & $\begin{array}{l}\text { Minimu } \\
\mathbf{m}\end{array}$ & $\begin{array}{l}\text { Maximu } \\
\mathbf{m}\end{array}$ \\
\hline Age & 257 & 34.23735 & 9.826328 & 17 & 65 \\
\hline Education & 257 & 9.645914 & 2.267965 & 4 & 15 \\
\hline Marital Status & 257 & 0.015564 & 0.2495131 & 0 & 4 \\
\hline Distance to nearest Transformer & 257 & 1.46642 & 0.6958715 & 0.01 & 2.9 \\
\hline Capital & 257 & 400782.1 & 336936.1 & 20000 & 3600000 \\
\hline Farm Size & 257 & 4.700389 & 2.636826 & 1 & 12 \\
\hline
\end{tabular}

Figure 3.1 shows the distribution of SMEs owner by gender of which the numbers of male SMEs owner were $159(62 \%)$ while female owners were $98(38 \%)$ of which this is concurrent to the national baseline survey report which shows that male SMEs owners in rural areas of Tanzania entails $32.3 \%$, female were $17.7 \%$ and those owned nd managed by both males and females were 47.1\% (National MSME Baseline Survey, 2012).

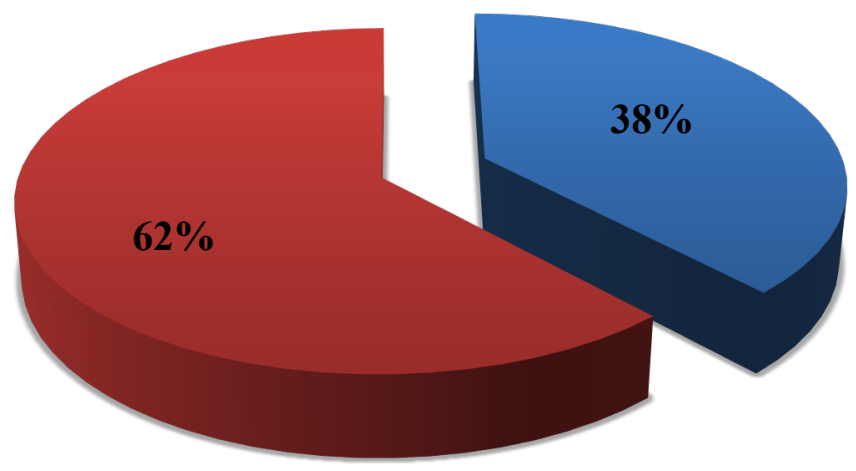

Female SMEs Owners

- Male SMEs Owners

Figure 3.1: Distribution of SMEs Owner by Gender 


\subsection{Regression Results}

In order to establish good analysis on the effects of rural electrification programs; an analysis on the determinants for the electricity adoption has been made in order to capture the clear picture on the effects

\subsubsection{Determinants of Electricity Adoption}

\begin{tabular}{l|l}
\hline & Probit \\
\hline Gender & 0.0853705 \\
Male $=1$ & {$[0.2388851]$} \\
Female $=0$ & \\
\hline Age & $0.0337133^{* * *}$ \\
& {$[0.0116483]$} \\
\hline Years of Schooling & $0.0829076^{*}$ \\
& {$[0.0453649]$} \\
\hline Marital Status & $0.6549307^{* * *}$ \\
Married $=1$ & {$[0.2284346]$} \\
Single $=0$ & \\
\hline Farm size & 0.0522817 \\
& {$[0.0380566]$} \\
\hline Distance to nearby Transformer & $0.3834045^{* * *}$ \\
& {$[0.1364013]$} \\
\hline Dummy of affording electrical cost in business & -0.0450976 \\
& {$[0.237839]$} \\
\hline Years of experience in business & -0.0189352 \\
& {$[0.0305586]$} \\
\hline Capital & $3.54 \mathrm{e}-07$ \\
& {$[3.64 \mathrm{e}-07]$} \\
\hline SMEs Revenues & $0.593852^{* * *}$ \\
& {$[0.1136861]$} \\
\hline Strength of Instrument & \\
Pseudo R square & 0.2594 \\
Chi 2 & 0.0000 \\
Number of observation & 257 \\
\hline
\end{tabular}

$* * *, * * *$ and $*$ show significance level at $1 \%, 5 \%$ and $10 \%$ respectively. Standard errors are in parenthesis.

SMEs revenues, years of schooling (education), gender, farm size and capital have been found to influence entrepreneurs' decision to adopt the usage of electricity positively despite not being statistically significant.

On the other hand, education measured in years of schooling has been found to influence electricity adoption by 8.290 percent. Married entrepreneurs have higher chances of adopting electricity by 65.493 percent comparing to single or unmarried entrepreneurs.

On top of that, distance to the nearby transformer increases probability of SMEs' decision to adopt electricity by 38.340 percent; therefore the more transformers are built closer to SMEs activities the more it influences their decisions to adopt it. 
Moreover, SMEs revenues have been also found to influence entrepreneurs' decisions on adopting the use of electricity by 59.385 percent of which this can further be interpreted as entrepreneurs with higher revenues have higher chances of adopting electrical usage.

\subsubsection{Effects of Rural Electrification Programs on SMEs Performances}

Results presented in odds ratio at Column 2 of Table 4 shows that variables such as gender, education measured in years of schooling, credit membership willingness to pay, distance to the nearby transformer, ability of the SMEs to afford cost of paying REA, years of experience in business, business capital and operating costs are significant factors in the study while factors like age, marital status, farm size and household electrified by REA were not statistically significant.

Female SMEs business owners whose household have been electrified by REA are experiencing an increase in the odds of getting higher revenues by 1.249 times greater than males SMEs business owners. This is seconded by the study of Shamdur et al., (2012) who found that females' entrepreneurs enjoy higher revenues than male in India.

On the other hand, the odds of SMEs owner with higher education measured in number of years of schooling is 1.313 higher in getting higher revenues and performing well in business than SMEs owner that have less number of years of schooling revenue compared to those who have spent fewer years in education at schools when all factors are remained constant.

An increase in the willingness of the SMEs to pay for the REA electrification services increases the odds of SMEs having higher revenues and enjoying good business performances by 2.149 higher than those who are not willing to pay for the energy. This result is concurrent with the study made by Obeng (2007) in Ghana who found that SMEs willingness to pay for the energy increases their monthly revenues comparing to those who quit from the energy use and turned into other sources of energy other than rural electrification. Moreover, when the cost of paying REA is increasing its odds reduces chances of SMEs having higher revenues comparing to uncertainty related with decision and perception of increasing costs.

Table 4: Ordered Logistic Regression

\begin{tabular}{|c|c|c|c|}
\hline & ologit & Odds Ratio & $\begin{array}{l}\text { Marginal } \\
\text { Effects }\end{array}$ \\
\hline $\begin{array}{l}\text { Gender } \\
\text { Male }=1 \\
\text { Female }=0\end{array}$ & $\begin{array}{l}1.249467^{* * *} \\
{[0.4205253]}\end{array}$ & $\begin{array}{l}3.488482^{* * *} \\
{[1.466995]}\end{array}$ & $\begin{array}{l}-0.0587919^{* *} \\
{[0.01972]}\end{array}$ \\
\hline Age & $\begin{array}{l}-0.0948171 \\
{[0.0874236]} \\
\end{array}$ & $\begin{array}{l}0.9095393 \\
{[0.0795152]}\end{array}$ & $\begin{array}{l}0.0053736 \\
{[0.00504]} \\
\end{array}$ \\
\hline Age squared & $\begin{array}{l}0.0013997 \\
{[0.0011596]}\end{array}$ & $\begin{array}{l}1.001401 \\
{[0.0011613]}\end{array}$ & $\begin{array}{l}-0.0000793 \\
{[0.00007]}\end{array}$ \\
\hline Years of Schooling & $\begin{array}{l}0.2727012^{* * *} \\
{[0.0660406]}\end{array}$ & $\begin{array}{l}1.313508^{* * * *} \\
{[0.0867448]}\end{array}$ & $\begin{array}{l}-0.0154548^{* * *} \\
{[0.00455]}\end{array}$ \\
\hline $\begin{array}{l}\text { Dummy of Marital Status } \\
\text { Married }=1 \\
\text { Single }=0\end{array}$ & $\begin{array}{l}-0.4546439 \\
{[0.3357022]}\end{array}$ & $\begin{array}{l}0.634674 \\
{[0.2130614]}\end{array}$ & $\begin{array}{l}0.0253351 \\
{[0.019]}\end{array}$ \\
\hline $\begin{array}{l}\text { Dummy of Credit Membership } \\
\text { Member of Credit } \\
\text { Not Member }\end{array}$ & $\begin{array}{l}1.367808^{* * *} \\
{[0.4129186]}\end{array}$ & $\begin{array}{l}3.926732^{* * *} \\
{[1.621421]}\end{array}$ & $\begin{array}{l}-0.1078945^{* *} \\
{[0.04562]}\end{array}$ \\
\hline
\end{tabular}




\begin{tabular}{|c|c|c|c|}
\hline Farm size & $\begin{array}{l}-0.0646493 \\
{[0.0587497]} \\
\end{array}$ & $\begin{array}{l}0.9373962 \\
{[0.0550717]} \\
\end{array}$ & $\begin{array}{l}0.0036639 \\
{[0.00336]} \\
\end{array}$ \\
\hline $\begin{array}{l}\text { Dummy of Willingness to Pay } \\
\text { Willing to Pay }=1 \\
\text { Not Willing to Pay }=0\end{array}$ & $\begin{array}{l}0.7650367^{* * *} \\
{[0.3413827]}\end{array}$ & $\begin{array}{l}2.149073^{* *} \\
{[0.7336565]}\end{array}$ & $\begin{array}{l}-0.0469299^{* *} \\
{[0.02388]}\end{array}$ \\
\hline Distance to nearby Transformer & $\begin{array}{l}-0.3634139^{*} \\
{[0.2008998]}\end{array}$ & $\begin{array}{l}0.6952986^{*} \\
{[0.1396853]}\end{array}$ & $\begin{array}{l}0.0205958^{*} \\
{[0.01195]}\end{array}$ \\
\hline $\begin{array}{l}\text { Dummy of affording electrical cost in } \\
\text { business }\end{array}$ & $\begin{array}{l}2.136546^{* * *} \\
{[0.3857013]}\end{array}$ & $\begin{array}{l}8.470133^{* * *} \\
{[3.266941]}\end{array}$ & $\begin{array}{l}-0.1830599^{* * *} \\
{[0.05122]}\end{array}$ \\
\hline $\begin{array}{l}\text { Dummy of SMEs household electrified } \\
\text { by REA } \\
\text { Electrified }=1 \\
\text { Not electrified }=0\end{array}$ & $\begin{array}{l}0.3556335 \\
{[0.3747453]}\end{array}$ & $\begin{array}{l}1.427084 \\
{[0.5347932]}\end{array}$ & $\begin{array}{l}0.0183508 \\
{[0.01768]}\end{array}$ \\
\hline $\begin{array}{l}\text { Dummy of Increasing cost } \\
\text { Increasing cost }=1 \\
\text { Uncertainty }=0\end{array}$ & $\begin{array}{l}-1.711018^{* * *} \\
{[0.4541463]}\end{array}$ & $\begin{array}{l}0.1806817^{* * *} \\
{[0 . .0820559]}\end{array}$ & $\begin{array}{l}0.1621815^{* *} \\
{[0.06422]}\end{array}$ \\
\hline $\begin{array}{l}\text { Dummy of Decreasing cost } \\
\text { Decreasing cost }=1 \\
\text { Uncertainty }=0\end{array}$ & $\begin{array}{l}-1.320476^{* * * *} \\
{[0.3640058]}\end{array}$ & $\begin{array}{l}0.2670081^{* * *} \\
{[0.0971925]}\end{array}$ & $\begin{array}{l}0.0958262^{* *} \\
{[0.03401]}\end{array}$ \\
\hline Years of experience in business & $\begin{array}{l}0.2085332^{* * *} \\
{[0.0510564]}\end{array}$ & $\begin{array}{l}1.23187^{* * *} \\
{[0.0628949]}\end{array}$ & $\begin{array}{l}-0.0118182^{* * *} \\
{[0.00353]}\end{array}$ \\
\hline Capital & $\begin{array}{l}1.14 \mathrm{e}-06^{* *} \\
{[5.67 \mathrm{e}-07]} \\
\end{array}$ & $\begin{array}{l}1.000001^{* *} \\
{[5.67 \mathrm{e}-07]}\end{array}$ & $\begin{array}{l}-6.44 \mathrm{e}-08^{* *} \\
{[0.00000]}\end{array}$ \\
\hline Average operating cost & $\begin{array}{l}1.19937^{* * *} \\
{[0.19596]} \\
\end{array}$ & $\begin{array}{l}3.318026^{* * *} \\
{[0.6502003]}\end{array}$ & $\begin{array}{l}-0.067972^{* * *} \\
{[0.01532]}\end{array}$ \\
\hline \multicolumn{4}{|l|}{ Strength of Instrument } \\
\hline Pseudo R square & 0.3616 & 0.3616 & \\
\hline Chi 2 & 0.0000 & 0.0000 & \\
\hline Number of observation & 257 & 257 & \\
\hline
\end{tabular}

***,*** and ${ }^{*}$ show significance level at $1 \%, 5 \%$ and $10 \%$ respectively. Standard errors are in parenthesis.

An entrepreneur with higher years of experience in the use of REA energy source in their businesses has greater odds of having higher revenues by 1.231 emphasizing that increase in years of experience increase ability for these SMEs to find better means of acquiring higher income compared to those with fewer years' counterparts. These results are similar to the findings obtained by Tarun and Ambarish (2013) when examining impacts of rural electrification to SMEs of which showed that SMEs owner with more years of experience in the use of this energy source had more revenues comparing to those with less years of experience.

SMEs capital was found to be a significant predictor of what an entrepreneur gets in terms of revenue after adopting rural electricity. Therefore an increase in SMEs business capital by 1 Tshs increases odds of SMEs to earn more revenues through their activities. Hence, those who had good business performances in Mvomero were more likely to have higher business capitals compared to those whose performance was fair or bad. 
Nonetheless, an increase in the average distance to the nearby transformer by $1 \mathrm{~km}$ increases odds of having higher revenue by 0.695 due to the multiplicative effects of unit energy price, distance that lead to the increase of SMEs products' prices and later lead to the increase in the SMEs revenues. This can be justified with the results shown at Column 1 in Table 3 which shows that an average increase of distance the nearby transformer reduces the SMEs revenues by $36 \%$. Therefore, those who stay nearer to the transformer were more likely to get higher SMEs revenue compared to those who stay far from the transformer, when all factors are remained constant.

In addition to the above findings, entrepreneurs being members of credit association increases odds of having higher revenues by 3.926 than those who are not members of any credit association.Through being members they are getting loans which help them paying for electrical bills that enhance the increase in the revenues. The results are similar to the study made by Akpan et al., (2007) in Nigeria that indicated that being member of credit association increase chance for both having better SMEs performances and rural electrification by $22 \%$.

There is a notion that married couples earn more comparing to singles. Results on Table 4 Column 2 show that the odds ratio of married SMEs owner having higher revenues is 0.634 . These findings are consistent with those of Shahidur et al., (2012) who argued that couples tend to support each other in various activities to increase the household and business income in different adversities.

SMEs owners who are engaging in the agricultural actives have odds ratio of 0.937 in earning higher revenues from businesses comparing to SMEs owners who are only engaging in business activities alone. This has been further documented by Tarun et al., (2013) that SMEs who are engaging in agricultural activities can use income generated from agriculture to stimulate growth of their businesses at times when their business are growing slowly and hence overcome numerous business challenges.

Testing Model Assumptions

Table 5: Brant Test Results

\begin{tabular}{|c|c|c|c|c|c|}
\hline & $\mathrm{Chi}^{2}$ & $d f$ & $P>C h i^{2}$ & ASL & {$\left[\begin{array}{lll}{[95 \%} & \mathrm{MC} & \mathrm{CI}\end{array}\right.$} \\
\hline Brant & 124.9 & 32 & 0.000 & 0.001 & 0.000 \\
\hline
\end{tabular}

There are several ways of testing proportional odds or parallel lines assumptions of the ordered logit model with the famous one being brant test which clarifies exact assumption. Table 5 brant test results shows results for each individual independent variable.

Table 6: Tests of the Parallel Regression Assumption (Oparallel Test)

\begin{tabular}{l|c|c|c}
\hline & $\boldsymbol{C h i}^{\mathbf{2}}$ & $\boldsymbol{d f}$ & $\boldsymbol{P}>\boldsymbol{C h i}^{\mathbf{2}}$ \\
\hline Wolfe Gould & 124.9 & 32 & 0.000 \\
\hline Brant & 72.97 & 32 & 0.000 \\
\hline Score & 134.5 & 32 & 0.000 \\
\hline Likelihood ratio & 149.9 & 32 & 0.000 \\
\hline Wald & 74.27 & 32 & 0.000 \\
\hline
\end{tabular}

A significant test static at Table 6 provides evidence that the parallel regression assumptions has been violated of which is due to fact that the sample is small hence it is not at all unusual to find out that proportional odds assumptions is violated. 
Table 7: Chi Square

\begin{tabular}{l|c|c|c}
\hline \multirow{2}{*}{$\begin{array}{l}\text { SMEs level of Performance based } \\
\text { on Revenues collected }\end{array}$} & \multicolumn{2}{|c|}{ Home/Residence Electrified by REA } & \multirow{2}{*}{ Total } \\
\cline { 2 - 3 } & No & Yes & \\
\hline Less than Tshs 300,000 & 19 & 34 & 53 \\
\hline Between Tshs 300,000 and 500,000 & 6 & 50 & 56 \\
\hline Between Tshs 500,000 and 800,000 & 16 & 63 & 69 \\
\hline Tshs 800,000 and above & 8 & 61 & $\mathbf{2 5 7}$ \\
\hline Total & $\mathbf{4 9}$ & $\mathbf{2 0 8}$ & \\
\hline Pearson $\mathrm{Chi}^{2}(3)=14.7742$ & & \\
\hline $\mathrm{Pr}=0.002$
\end{tabular}

\section{Conclusion}

The principal finding emerging from this study justifies that REA programs enhances the growth of businesses and employment creations. As observed from Mvomero district of which 257 SMEs owners who are electrified by REA from Melela, Mlali, Doma and Mgeta wards provision of grid access improves the performance of Small and Medium Enterprises. A clearly positive effect of electrification can be observed by the creation of electricity reliant firms in the access region. They use more electric appliances and have better market access because they offer new products to the local population as well as selling semi-finished products to other enterprises in the Mvomero region.

As a consequence, the reliant firms perform better and generate income exceeding those of other connected and non-connected manufacturing firms. Nevertheless, potential crowding out effects on firms that had existed already before electrification potentially reduces the net effect on the local economy. Therefore, the study have justified that increase accessibility and affordability of Rural Electrification programs have multiplier effects in the growth of SMEs business and increase in the level of the SMEs performances measured in revenues collected by these SMEs.

\section{Policy Implications}

The following are the policy implications based on the major findings and conclusions. First, limited market access in Morogoro region can be suspected to be major reason for weak productive take up of electricity. Hence, if substantial productive electricity uses are desired, the electrification programs should preferentially be targeted at regions that have sufficient market potential to accommodate expanded production as it has found in this study that REA programs have positive impacts in the creation and increase or expansion of the available markets. Second, based on the findings at Table 4 the project should be accompanied by technical and possibly financial assistance to assess productive use potentials as it has been found that having stable and high capital increases chances for the SMEs to adopt Rural Electrification Programs as well as experiencing high revenues. In this regard, business development services can raise awareness about cost structures and existent and non-existent market opportunities. Third, improved access to credits can serve in helping manufacturers to finance the costs of switching to electrified production. Such assistance has to be open towards the result. Finally, to ensure that there are sufficient funds for electrification projects, there is need tohave sufficient, timelyand fairly distributed government disbursements of funds in the project of rural electrification to the projects. Through this it helps the implementation of grid extension into areas that are not connected to the grids 


\section{Reference}

Akpan, U. Essien, M. and Isihak, S. (2013). Impact of Rural Electrification on Rural SMEs in Niger Delta, Nigeria. Energy for Sustainable Development,17, pp. 504-509.

Antoine V., Jane N.O.K., Vivian G., Gerard G., and Abubakar S. Bahaj, (2017). How does energy matter? Rural electrification, entrepreneurship, and community development in Kenya. Energy Policy. Published by Elsevier Ltd. journal homepage: www.elsevier.com/locate/enpol.

Balla, J. (2003). Paper Presented at the World Summit on Sustainable Development. Johannesburg, South Africa. pp. $1-12$.

Gerald M., Lewis M. and Yeukai M.D. (2018). The Significance of Rural Electrification in Zimbabwe: A Case Study of Mudzi District, Mashona and East Province, Zimbabwe. Research journals. Journal of Public Policy Vol. 3 । No. 2 https://www.researchgate.net/publication/308339388.

Grimm, M., Hartwig, R. and Lay, J. (2012) How Much Does Utility Access Matter for the Performance of Small and Medium Entreprises? Accessed from http://wwwwds.worldbank.org/external/default/WDSContentServer/WDSP/IB/2013/05/ 24/000333037 20130524141223/Rendered/PDF/779350 WP0P11510BLIC00PublicServices.pdf

KidoleV.V. (2015). Contribution of Rural Electrification to Household Income in Moshi District, Tanzania. A dissertation submitted in partial fulfillment of the requirements for the degree of Master of Arts in rural development of Sokoine University of agriculture. Morogoro, Tanzania.

Kirubi, C., Jacobson, A., Kammen, D., \& Mills, A. (2008). Community-based electric microgrids can contribute to rural development: Evidence from Kenya. World Development, 37(7), $1208-1221$.

Kothari C.R. (2004:2008). Research Methodology. New Age International Publisher

Maleko G.C.(2005). Impact of electricity services on Small and Medium Entreprises in rural areas in Tanzania" A thesis submitted for the award of master of environmental business administration (environmental and energy management) department of energy and sustainable development University of Twente, Enscheda, Netherlands.

Obeng, G.Y. (2007). Solar PV rural electrification assessing energy poverty and impacts on quality of life in rural Ghana. Thesis for Award of Kwame Nkrumah University, Kumasi, Ghana. 258pp.

Person, R. and Swanson, G. (1996). Analysis of improving performance "Cerebral Context." Vocational Education Journal 74 (3): 18-21, 30.

Sawe E.N. (2004). "Brief on Energy Sector in Tanzania". Renewable Energy and Environmental News, (TaTEDO), ISSN 0856-6704.

Shahidur R. K., Hussain A. Samad, Rubaba Ali and Douglas F. Barnes, (2012). Who Benefits Most from Rural Electrification? Evidence in India. Agricultural \& Applied Economics Association's 2012 AAEA Annual Meeting, Seattle, Washington.

Tanzania Electrical Supply Company (TANESCO) 2016, 2017 and 2018 Report 
Tarun K.B., Reaz U, Ambarish M., (2013). Impacts of Electricity Access to Rural SMEs. International Journal of Managing Value and Supply Chains (IJMVSC) Vol.4, No. 4. DOI: 10.5121/ijmvsc.2013.4402.

World Bank (2008:2015:2017:2020) The Welfare Impact of Rural Electrification: A Reassessment of the Costs and Benefits, An IEG Impact Evaluation, World Bank.

Ng'ang'a, S.I., Onyango, G.M and Kerre, B.W. (2009). Collective Efficiency and the Small Enterprise Growth in Kenya. Retrieved January, 2019, fromhttp://www.ajol.info/index.php/kjbm/article/download/65970/53674.

United Republic of Tanzania, (2018). Power System Master Plan 2012 update. Ministry of Energy and Minerals

National Baseline Survey Report for Micro, Small, and Medium Enterprises in Tanzania December 2012. Financial Sector Deepening Trust. 


\section{APPENDICES}

\section{Appendix A}

\section{Determinants of Electrical Adoption among SMEs}

- probit Adoptel Dgender Age Educ DMarital FarmSize Distance DAfford Experinc Capital SMEReven

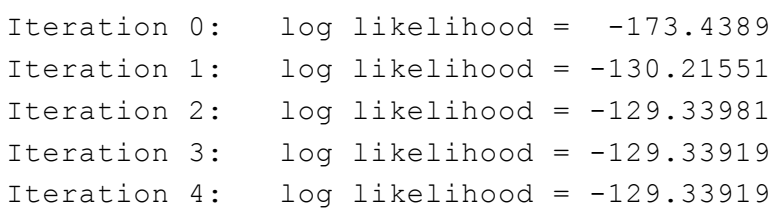

\begin{tabular}{r|rrrrrr}
\hline Adoptel & Coef. & Std. Err. & z & P > z l & [95\% Conf. Interval] \\
\hline Dgender & .0853705 & .2388851 & 0.36 & 0.721 & -.3828356 & .5535767 \\
Age & .0337133 & .0116483 & 2.89 & 0.004 & .0108831 & .0565435 \\
Educ & .0829076 & .0453649 & 1.83 & 0.068 & -.006006 & .1718211 \\
DMarital & .6549307 & .2284346 & 2.87 & 0.004 & .2072072 & 1.102654 \\
FarmSize & .0522817 & .0380566 & 1.37 & 0.170 & -.0223079 & .1268713 \\
Distance & .3834045 & .1364013 & 2.81 & 0.005 & .1160629 & .6507461 \\
DAfford & -.0450976 & .237839 & -0.19 & 0.850 & -.5112535 & .4210583 \\
Experinc & -.0189352 & .0305586 & -0.62 & 0.535 & -.0788291 & .0409586 \\
Capital & $3.54 e-07$ & $3.64 e-07$ & 0.97 & 0.331 & $-3.59 e-07$ & $1.07 e-06$ \\
SMEReven & .593852 & .1136861 & 5.22 & 0.000 & .3710314 & .8166726 \\
_cons & -4.383992 & .7837607 & -5.59 & 0.000 & -5.920134 & -2.847849 \\
\hline
\end{tabular}




\section{Appendix B}

\section{Effects of Rural Electrification Programs on SMEs Performances (SMEs revenues)}

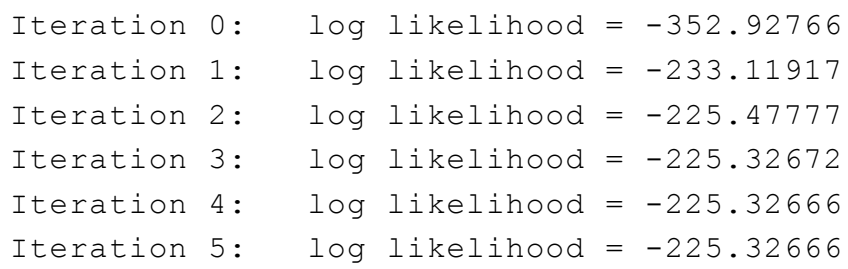

\begin{tabular}{|c|c|c|c|c|c|c|}
\hline SMEReven & Coef. & Std. Err. & z & $P>|z|$ & [95\% Conf. & Interval] \\
\hline Dgender & 1.249467 & .4205253 & 2.97 & 0.003 & .4252524 & 2.073681 \\
\hline Age & -.0948171 & .0874236 & -1.08 & 0.278 & -.2661643 & .0765301 \\
\hline Age_Sq & .0013997 & .0011596 & 1.21 & 0.227 & -.0008731 & .0036726 \\
\hline Educ & .2727012 & .0660406 & 4.13 & 0.000 & .1432641 & .4021384 \\
\hline DMarital & -.4546439 & .3357022 & -1.35 & 0.176 & -1.112608 & .2033203 \\
\hline DCredit & 1.367808 & .4129186 & 3.31 & 0.001 & .558502 & 2.177113 \\
\hline Farmsize & -.0646493 & .0587497 & -1.10 & 0.271 & -.1797965 & .0504979 \\
\hline DWTP & .7650367 & .3413827 & 2.24 & 0.025 & .0959389 & 1.434135 \\
\hline Distance & -.3634139 & .2008998 & -1.81 & 0.070 & -.7571702 & .0303425 \\
\hline DAfford & 2.136546 & .3857013 & 5.54 & 0.000 & 1.380586 & 2.892507 \\
\hline DREA & .3556335 & .3747453 & 0.95 & 0.343 & -.3788537 & 1.090121 \\
\hline DIC & -1.320476 & .3640058 & -3.63 & 0.000 & -2.033914 & -.6070379 \\
\hline $\mathrm{DDC}$ & -1.711018 & .4541463 & -3.77 & 0.000 & -2.601129 & -.8209078 \\
\hline Experinc & .2085332 & .0510564 & 4.08 & 0.000 & .1084645 & .308602 \\
\hline Capital & $1.14 \mathrm{e}-06$ & $5.67 e-07$ & 2.01 & 0.045 & $2.62 e-08$ & $2.25 e-06$ \\
\hline OperCost & 1.19937 & .19596 & 6.12 & 0.000 & .8152955 & 1.583444 \\
\hline /cut 1 & 4.423825 & 1.777539 & & & .9399126 & 7.907738 \\
\hline / cut 2 & 6.307169 & 1.811375 & & & 2.756939 & 9.857399 \\
\hline / cut 3 & 9.11114 & 1.856692 & & & 5.472091 & 12.75019 \\
\hline
\end{tabular}




\section{Appendix C}

\section{Marginal Effects to measure Effects of Rural Electrification Programs on SMEs Performances (SMEs revenues)}

- $\operatorname{mfx}$

Marginal effects after ologit

$\mathrm{y}=\operatorname{Pr}(\mathrm{SMEReven}=1) \quad($ predict $)$ $=.06031044$

\begin{tabular}{|c|c|c|c|c|c|c|c|}
\hline variable & $d y / d x$ & std. Err. & z & $P>|z|$ & $95 \%$ & C.I. & $\mathrm{X}$ \\
\hline Dgender* & -.0587919 & .01972 & -2.98 & 0.003 & -.097435 & -.020149 & .291829 \\
\hline Age & .0053736 & .00504 & 1.07 & 0.287 & -.004508 & .015255 & 34.2374 \\
\hline Age_Sq & -.0000793 & .00007 & -1.18 & 0.237 & -.000211 & .000052 & 1268.38 \\
\hline Educ & -.0154548 & .00455 & -3.39 & 0.001 & -.024378 & -.006532 & 9.64591 \\
\hline DMarital* & .0253351 & .019 & 1.33 & 0.182 & -.011906 & .062576 & .55642 \\
\hline DCredit* & -.1078945 & .04562 & -2.36 & 0.018 & -.197314 & -.018475 & .747082 \\
\hline Farmsize & .0036639 & .00336 & 1.09 & 0.275 & -.002916 & .010244 & 4.70039 \\
\hline DWTP* & -.0469299 & .02388 & -1.97 & 0.049 & -.093735 & -.000125 & .595331 \\
\hline Distance & .0205958 & .01195 & 1.72 & 0.085 & -.002834 & .044026 & 1.46642 \\
\hline DAfford* & -.1830599 & .05122 & -3.57 & 0.000 & -.283458 & -.082661 & .677043 \\
\hline DREA * & -.0183508 & .01768 & -1.04 & 0.299 & -.052998 & .016297 & .190661 \\
\hline $\mathrm{DIC} \star$ & .0958262 & .03401 & 2.82 & 0.005 & .029175 & .162478 & .319066 \\
\hline $\mathrm{DDC} *$ & .1621815 & .06422 & 2.53 & 0.012 & .036322 & .288041 & .178988 \\
\hline Experinc & -.0118182 & .00353 & -3.35 & 0.001 & -.018728 & -.004908 & 5.51556 \\
\hline Capital & $-6.44 e-08$ & .00000 & -1.94 & 0.052 & $-1.3 e-07$ & $5.5 e-10$ & 400782 \\
\hline OperCost & -.067972 & .01532 & -4.44 & 0.000 & -.098005 & -.037939 & 2.38911 \\
\hline
\end{tabular}

(*) dy/dx is for discrete change of dummy variable from 0 to 1 


\section{Appendix D}

\section{Tests of Parallel Regression Assumption}

- oparallel

Tests of the parallel regression assumption

\begin{tabular}{r|ccc} 
& Chi2 & df & P>Chi2 \\
\hline Wolfe Gould & 124.9 & 32 & 0.000 \\
Brant & 72.97 & 32 & 0.000 \\
score & 134.5 & 32 & 0.000 \\
likelihood ratio & 149.9 & 32 & 0.000 \\
Wald & 74.27 & 32 & 0.000
\end{tabular}

- oparallel, brant asl mcci nodots

Test of the parallel regression assumption

\begin{tabular}{l|llllll} 
& Chi2 & df & P>Chi2 & ASL & {$[95 \%$} & MC CI ] \\
\hline Brant & 258 & 30 & 0.000 & 0.002 & 0.000 & 0.006
\end{tabular}

